\title{
Suspension two-layered blood flow through a bell shaped stenosis in arteries
}

\author{
Amit Medhavi* \\ Department of Mechanical Engineering, Kamla Nehru Institute of Technology, Sultanpur, India
}

\begin{abstract}
The present study concerns with the effects of the hematocrit and the peripheral layer on blood flow characteristics due to the presence of a bell shaped stenosis in arteries. To account for the hematocrit and the peripheral layer, the flowing blood has been represented by a two-layered macroscopic two-phase (i.e., a suspension of red cells in plasma) model. The expressions for the flow characteristics, namely, the velocity profiles, the flow rate, the impedance, the wall shear stress in the stenotic region and the shear stress at the stenosis throat have been derived. The quantitative effects of the hematocrit and the peripheral layer on these flow characteristics have been displayed graphically and discussed briefly.
\end{abstract}

Keywords: Hematocrit, impedance, shear stress, throat, erythrocytes, suspension

\section{Introduction}

The frequently occurring cardiovascular disease, stenosis or arteriosclerosis means narrowing of any body passage, tube or orifice, is known to be responsible for many of the serious consequences (cerebral strokes, myocardial infarction, angina pectoris, cardiac arrests). Although, the etiology of the initiation of disease is not well understood, however, it is believed that the disease occurs due to the deposits of the cholesterol, fatty substances, cellular waste products, calcium and fibrin in the inner lining of an artery. It is also well established that once the constriction has developed, it brings about the significant changes in the flow field, particularly, the pressure distribution, the wall shear stress and the impedance (flow resistance). With the knowledge that the cardiovascular disease, stenosis is closely associated with the flow conditions and other hemodynamic factors, a large number of researchers including Young [41, 48], Young and Tsai [39], Caro et al. [7], Shukla et al. [29], Ahmed and Giddens [1],

*Corresponding author: Amit Medhavi, Department of Mechanical Engineering, Kamla Nehru Institute of Technology, Sulanpur228118, India. E-mail: amitmedhavi@yahoo.co.in.
Sarkar and Jayaraman [28], Pralhad and Schultz [27], Jung et al. [11], Liu et al. [13], Srivastava and Raastogi [33, 34], Misra and Shit [21], Ponalagusamy [26], Layek et al. [12], Joshi et al. [10], Mekheimer and ElKot [18], Tzirtzilakis [38], Mandal and coworkers [14, 15], Politis et al. [23, 24], Singh et al. [30], Biswas and Chakraborty [4, 5], Medhavi [17], Mishra and Siddiqui [20], Nadeem et al. [22], Mekheirmer et. al. [19], Ponalagusamy and Selvi [25], Bandyopadhyay and Layek $[2,3]$, Srivastava et al. [36] and many others have addressed the stenotic development problems under various flow situations since the first investigation of Mann et al. [16].

Being a suspension of corpuscles, at low shear rates blood in general behaves like a non-Newtonian fluid in small diameter tubes. The experimental observations of Cokelet [8] and theoretical investigation of Haynes [9] indicate that blood can no longer be treated as a single-phase homogeneous viscous fluid while flowing through narrow arteries (of diameter $\leq 1000 \mu \mathrm{m})$. Skalak [31] concluded that an accurate description of the blood in small vessels requires the consideration of erythrocytes as discrete particles. In addition, Bugliarello and Sevilla [6], Cokelet [8] and Thurston [37] have shown experimentally that for 


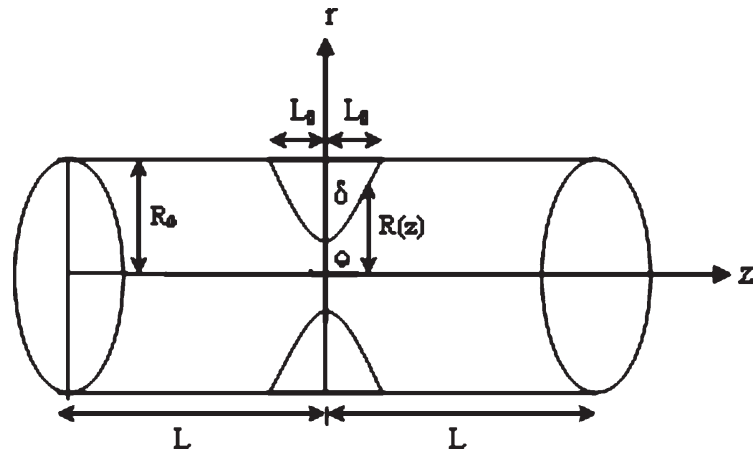

Fig. 1. The geometry of an arterial bell shaped stenosis.

blood flowing through small vessels, there is a cellfree plasma (Newtonian viscous fluid) layer and a core region of suspension of all the erythrocytes. Haynes [9] presented a two-fluid model for blood, consisting of a core region of suspension of all the erythrocytes as a homogeneous Newtonian viscous fluid and a cell-free plasma layer as a Newtonian fluid of constant viscosity (equal to the viscosity of water) and concluded that the significance of the peripheral layer increases with decreasing blood vessel diameter. A brief discussion and survey on suspension modeling of blood flow has been presented in Srivastava [32].

It is also known from the published literature that stenoses may develop in series (multiple stenoses), may be of irregular shapes, overlapping, bell shaped, composite in nature, axially symmetric or nonsymmetric, etc. The majority of the studies conducted have used axially symmetric and non-symmetric stenoses. The present work is devoted to discuss the flow through a bell shaped stenosis assuming that the flowing blood is represented by a two-layered suspension model [32]. The theoretical model used to conduct the study enables one to observe simultaneous effects of the hematocrit and the peripheral layer on flow characteristics of blood due to the presence of a bell shaped stenosis in arteries. The artery length is considered large enough as compared to its radius so that the entrance, end and special wall effects can be neglected.

\section{Formulation of the problem}

Consider the axisymmetric flow of blood in an artery of circular cross-section of radius $\mathrm{R}$ with an axisymmetric bell shaped stenosis. Assuming that the flowing blood is represented by a two-layered suspension model consisting of a central layer of suspension of all the erythrocytes (i.e., a suspension of red cells in plasma) of radius $R_{1}$ and a peripheral layer of plasma (a Newtonian viscous fluid) of thickness $\left(\mathrm{R}-\mathrm{R}_{1}\right)$. The stenosis geometry [21] and the shape of the central layer, assumed to be manifested in the arterial segment, are respectively described in Figs. 1 and 2, as

$$
\begin{aligned}
& \frac{\left(\mathrm{R}(\mathrm{z}), \mathrm{R}_{1}(\mathrm{z})\right)}{\mathrm{R}_{0}} \\
& =1-\frac{\left(\delta, \delta_{1}\right)}{\mathrm{R}_{0}} \exp \left(\frac{-\mathrm{m}^{2} \varepsilon^{2} \mathrm{z}^{2}}{\mathrm{R}_{0}^{2}}\right), \quad-\mathrm{L}_{0} \leq \mathrm{z} \leq \mathrm{L}_{0} \\
& =(1, \alpha), \quad \text { otherwise, }
\end{aligned}
$$

where $R_{0}$ is the radius of the arterial segment in the non-stenotic region, $R(z)$ is the radius of the stenosed portion located at the axial distance $\mathrm{z}$ from the left end of the segment, $\delta$ is the depth of stenosis at the throat and $\mathrm{m}$ is a parametric constant, $\varepsilon$ is the relative length of the constriction defined as the ratio of the radius to the half length of the stenosis, i.e., $\varepsilon=\mathrm{R}_{0} / \mathrm{L}_{0}$.

The equations describing a two-layered suspension blood flow [32] in the case of a mild stenosis $\left(\delta / R_{0}\right.$ $<<1$ ), are given as

$$
\begin{aligned}
&(1-C) \frac{d p}{d z}=(1-C) \frac{\mu_{s}(C)}{r} \frac{\partial}{\partial r}\left(r \frac{\partial}{\partial r}\right) u_{f} \\
&+C S\left(u_{p}-u_{f}\right), \quad 0 \leq r \leq R_{1}, \\
& C \frac{d p}{d z}= C S\left(u_{f}-u_{p}\right), \quad 0 \leq r \leq R_{1}, \\
& \frac{d p}{d z}=\frac{\mu_{0}}{r} \frac{\partial}{\partial r}\left(r \frac{\partial}{\partial r}\right) u_{0}, \quad R_{1} \leq r \leq R,
\end{aligned}
$$

where $r$ is the radial coordinate measured normal to the artery axis and $\mathrm{p}$ denotes the pressure, $\left(\mathrm{u}_{\mathrm{f}}, \mathrm{u}_{\mathrm{p}}\right)$ are the axial velocity of (fluid, particle) phases in the core region $\left(0 \leq \mathrm{r} \leq \mathrm{R}_{1}\right),\left(\mu_{0}, \mathrm{u}_{0}\right)$ are (viscosity, axial velocity) of fluid (plasma) in the peripheral region $\left(R_{1} \leq r \leq R\right), \mu_{S}(C) \cong \mu_{S}$ is the suspension viscosity (apparent or effective viscosity) in the core region, $\mathrm{C}$ denotes the constant [35] volume fraction density of the particles (called hematocrit), $\mathrm{S}$ is the drag coefficient of interaction exerted by one phase on the other, and the subscripts $f$ and $p$ denote the quantities associated with the plasma (fluid) and erythrocyte (particle) phases, respectively. The limitations and the usefulness 
of the present theoretical model are discussed briefly in Srivastava [32]. The expression for the viscosity of suspension, $\mu_{\mathrm{s}}$ and the drag coefficient of interaction, $\mathrm{S}$ for the present study are selected [35] as

$$
\begin{gathered}
\mu_{\mathrm{s}} \cong \mu_{\mathrm{s}}(\mathrm{C})=\frac{\mu_{\mathrm{o}}}{1-\mathrm{qC}}, \\
\mathrm{q}=0.07 \exp \left[2.49 \mathrm{C}+\left(\frac{1107}{\mathrm{~T}}\right) \exp (-1.69 \mathrm{C})\right] \\
\mathrm{S}=4.5\left(\mu_{\mathrm{o}} / \mathrm{a}_{\mathrm{o}}^{2}\right) \frac{4+3\left[8 \mathrm{C}-3 \mathrm{C}^{2}\right]^{1 / 2}+3 \mathrm{C}}{(2-3 \mathrm{C})^{2}}
\end{gathered}
$$

where $\mathrm{T}$ is measured in absolute scale of the temperature $(\mathrm{K}), \mu_{\mathrm{o}}$ is the constant plasma viscosity and $\mathrm{a}_{\mathrm{o}}$ is the radius of an erythrocyte.

The boundary conditions are the standard no slip conditions of velocities and the shear stresses at the tube wall and the interface, and are stated as

$$
\begin{gathered}
\mathrm{u}_{0}=0 \quad \text { at } \mathrm{r}=\mathrm{R}, \\
\mathrm{u}_{0}=\mathrm{u}_{\mathrm{f}} \quad \text { and } \quad \tau_{\mathrm{p}}=\tau_{\mathrm{f}} \quad \text { at } \mathrm{r}=\mathrm{R}_{1}, \\
\frac{\partial \mathrm{u}_{\mathrm{f}}}{\partial \mathrm{r}}=\frac{\partial \mathrm{u}_{\mathrm{p}}}{\partial \mathrm{r}}=0 \quad \text { at } \mathrm{r}=0,
\end{gathered}
$$

where $\tau_{\mathrm{p}}=\mu_{\mathrm{o}} \partial \mathrm{u}_{0} / \partial \mathrm{r}$ and $\tau_{\mathrm{f}}=(1-\mathrm{C}) \mu_{\mathrm{s}} \partial \mathrm{u}_{\mathrm{f}} / \partial \mathrm{r}$ are the shear stresses of the peripheral and central layers, respectively.

\section{Analysis}

The expressions for velocities, $\mathrm{u}_{0}, \mathrm{u}_{\mathrm{f}}$ and $\mathrm{u}_{\mathrm{p}}$ obtained as the solutions of Equations (2)-(4), subject to the boundary conditions (7)-(9), are given as

$$
\begin{gathered}
\mathrm{u}_{0}=-\frac{\mathrm{R}_{0}^{2}}{4 \mu_{0}} \frac{\mathrm{dp}}{\mathrm{dz}}\left\{\left(\mathrm{R} / \mathrm{R}_{0}\right)^{2}-\left(\mathrm{r} / \mathrm{R}_{0}\right)^{2}\right\}, \quad \mathrm{R}_{1} \leq \mathrm{r} \leq \mathrm{R}, \\
\mathrm{u}_{\mathrm{f}}=-\frac{\mathrm{R}_{\mathrm{o}}^{2}}{4(1-\mathrm{C}) \mu_{0}} \frac{\mathrm{dp}}{\mathrm{dz}}\left[\mu\left\{\left(\mathrm{R}_{1} / \mathrm{R}_{0}\right)^{2}-\left(\mathrm{r} / \mathrm{R}_{0}\right)^{2}\right\}\right. \\
\left.+(1-\mathrm{C})\left\{\left(\mathrm{R} / \mathrm{R}_{0}\right)^{2}-\left(\mathrm{r} / \mathrm{R}_{0}\right)^{2}\right\}\right], \\
0 \leq \mathrm{r} \leq \mathrm{R}_{1},
\end{gathered}
$$

$$
\begin{aligned}
& \mathrm{u}_{\mathrm{p}}=-\frac{\mathrm{R}_{\mathrm{o}}^{2}}{4(1-\mathrm{C}) \mu_{0}} \frac{\mathrm{dp}}{\mathrm{dz}}\left\{\mu\left[\left(\mathrm{R}_{1} / \mathrm{R}_{0}\right)^{2}-\left(\mathrm{r} / \mathrm{R}_{0}\right)^{2}\right]\right. \\
&\left.+(1-\mathrm{C})\left[\left(\mathrm{R} / \mathrm{R}_{0}\right)^{2}-\left(\mathrm{r} / \mathrm{R}_{0}\right)^{2}\right]+\frac{4(1-\mathrm{C}) \mu_{0}}{\mathrm{SR}_{0}^{2}}\right\}, \\
& 0 \leq \mathrm{r} \leq \mathrm{R}_{1},
\end{aligned}
$$

where $\mu=\mu_{0} / \mu_{s}$.

The flow flux, $\mathrm{Q}$ is now calculated as

$$
\begin{aligned}
\mathrm{Q}= & 2 \pi\left\{\int_{\mathrm{R}_{1}}^{\mathrm{R}} \mathrm{ru}_{0} \mathrm{dr}\right. \\
& \left.+\int_{0}^{\mathrm{R}_{1}} \mathrm{r}\left[(1-\mathrm{C}) \mathrm{u}_{\mathrm{f}}+\mathrm{C} \mathrm{u}_{\mathrm{p}}\right] \mathrm{dr}\right\} \\
= & -\frac{\pi \mathrm{R}_{\mathrm{o}}^{4}}{8(1-\mathrm{C}) \mu_{0}} \frac{\mathrm{dp}}{\mathrm{dz}}\left\{(1-\mathrm{C})\left[\left(\mathrm{R} / \mathrm{R}_{0}\right)^{4}-\left(\mathrm{R}_{1} / \mathrm{R}_{0}\right)^{4}\right]\right. \\
& \left.+\mu\left(\mathrm{R}_{1} / \mathrm{R}_{0}\right)^{4}+\beta\left(\mathrm{R}_{1} / \mathrm{R}_{0}\right)^{2}\right\},
\end{aligned}
$$

with $\beta=8 \mathrm{C}(1-\mathrm{C}) \mu_{0} / \mathrm{SR}_{0}^{2}$, a non-dimensional suspension parameter.

Using the fact that the total flux is equal to the sum of the fluxes across the two regions (peripheral and core), one determines the relations [32]: $\mathrm{R}_{1}=\alpha \mathrm{R}$ and $\delta_{1}=\alpha \delta$. In view of these relations, the pressure drop, $\Delta \mathrm{p}(=\mathrm{p}$ at $\mathrm{z}=-\mathrm{L},-\mathrm{p}$ at $\mathrm{z}=\mathrm{L})$ across the stenosis between the sections $\mathrm{z}=-\mathrm{L}$ and $\mathrm{z}=\mathrm{L}$, using the expression for $(-\mathrm{dp} / \mathrm{dz})$ obtained from Equation (13), is derived as

$$
\Delta \mathrm{p}=\int_{-\mathrm{L}}^{\mathrm{L}}\left(-\frac{\mathrm{dp}}{\mathrm{dz}}\right) \mathrm{dz}=\frac{8(1-\mathrm{C}) \mu_{0} \mathrm{Q}_{\mathrm{o}}}{\pi \mathrm{R}_{\mathrm{O}}^{4}} \psi
$$

where $\quad \psi=\int_{-\mathrm{L}}^{-\mathrm{L}_{0}}[\phi(\mathrm{z})]_{\mathrm{R} / \mathrm{R}_{\mathrm{o}}=1} \mathrm{dz}+\int_{-\mathrm{L}_{0}}^{\mathrm{L}_{\mathrm{o}}} \phi(\mathrm{z}) \mathrm{dz}$ $+\int_{\mathrm{L}_{0}}^{\mathrm{L}}[\phi(\mathrm{z})]_{R / R_{0}=1} \mathrm{dz}$,

$$
\begin{gathered}
\phi(\mathrm{z})=\frac{1}{\eta\left(\mathrm{R} / \mathrm{R}_{0}\right)^{4}+\beta \alpha^{2}\left(\mathrm{R} / \mathrm{R}_{0}\right)^{2}}, \\
\eta=(1-\mathrm{C})\left(1-\alpha^{4}\right)+\mu \alpha^{4} .
\end{gathered}
$$

The first and third integrals in the expression for $\psi$ obtained above are straight forward whereas the evaluation of the second integral in closed form is a 
formidable task and thus will be evaluated numerically. Using now the definitions from Srivastava and Rastogi [34], the expression for the impedance (flow resistance), $\lambda$ the wall shear stress, $\tau_{\mathrm{w}}$ and the shear stress at the stenosis throat, $\tau_{\mathrm{s}}$ are obtained in their non-dimensional form as

$$
\begin{aligned}
& \lambda=(1-\mathrm{C})\left\{\frac{1-\mathrm{L}_{0} / \mathrm{L}}{\eta+\beta \alpha^{2}}\right. \\
&\left.+\frac{1}{\mathrm{~L}} \int_{-\mathrm{L}_{0}}^{\mathrm{L}_{0}} \frac{\mathrm{dz}}{\eta\left(\mathrm{R} / \mathrm{R}_{0}\right)^{4}+\beta \alpha^{2}\left(\mathrm{R} / \mathrm{R}_{0}\right)^{2}}\right\}, \\
& \tau_{\mathrm{w}}=\frac{(1-\mathrm{C})}{\eta\left(\mathrm{R} / \mathrm{R}_{0}\right)^{3}+\beta \alpha^{2}\left(\mathrm{R} / \mathrm{R}_{0}\right)}, \\
& \tau_{\mathrm{s}}=\frac{(1-\mathrm{C})}{\eta\left(1-\delta / \mathrm{R}_{0}\right)^{3}+\beta \alpha^{2}\left(1-\delta / \mathrm{R}_{0}\right)},
\end{aligned}
$$

where

$$
\begin{aligned}
\lambda & =\bar{\lambda} / \lambda_{0},\left(\tau_{\mathrm{w}}, \tau_{\mathrm{s}}\right)=\left(\bar{\tau}_{\mathrm{w}}, \bar{\tau}_{\mathrm{s}}\right) / \tau_{0}, \\
\bar{\lambda} & =\Delta \mathrm{p} / \mathrm{Q}, \bar{\tau}_{\mathrm{w}}=(-\mathrm{R} / 2) \mathrm{dp} / \mathrm{dz}, \\
\overline{\tau_{\mathrm{s}}} & =[-(\mathrm{R} / 2)(\mathrm{dp} / \mathrm{dz})]_{\mathrm{R} / \mathrm{R}_{0}=\left(1-\delta / \mathrm{R}_{0}\right),} \\
\lambda_{0} & =16 \mu_{0} \mathrm{~L} / \pi \mathrm{R}_{0}^{4}, \tau_{0}=4 \mu_{0} \mathrm{Q} / \pi \mathrm{R}_{0}^{3},
\end{aligned}
$$

$\lambda_{0}$ and $\tau_{0}$ are the impedance and shear stress in a normal (no stenosis) artery for a Newtonian fluid (i.e., $\mathrm{C}=0$ ), and $\left(\bar{\lambda}, \overline{\tau_{\mathrm{w}}}, \overline{\tau_{\mathrm{s}}}\right)$ are (impedance, wall shear stress, shear stress at the stenosis throat) in their dimensional form.

When the core mixture behaves like a Newtonian fluid of constant viscosity, $\mu_{1}$ (different from $\mu_{0}$ ), the results obtained above reduce to the case of a two-fluid model of Newtonian fluid as

$$
\begin{gathered}
\lambda_{\mathrm{t}}=\gamma\left\{1-\mathrm{L}_{0} / \mathrm{L}+(1 / \mathrm{L}) \int_{-\mathrm{L}_{0}}^{\mathrm{L}_{0}} \frac{\mathrm{dz}}{\left(\mathrm{R} / \mathrm{R}_{0}\right)^{4}}\right\}, \\
\tau_{\mathrm{wt}}=\frac{\gamma}{\left(\mathrm{R} / \mathrm{R}_{0}\right)^{3}}, \\
\tau_{\mathrm{st}}=\frac{\gamma}{\left(1-\delta / \mathrm{R}_{0}\right)^{3}},
\end{gathered}
$$

with $\gamma=1 /\left[1-\left(1-\mu^{\prime}\right) \alpha^{4}\right], \mu^{\prime}=\mu_{0} / \mu_{1}$. The second subscript $t$ denotes the quantities associated with the two-fluid model of Newtonian fluids.
In the absence of the peripheral layer (i.e., $\alpha=1$ ), the expressions for the flow characteristics obtained in Equations (15)-(18), derive the corresponding results for the case of a single-layered macroscopic two-phase blood flow as

$$
\begin{aligned}
\lambda_{\mathrm{m}}= & (1-\mathrm{C})\left\{\frac{1-\mathrm{L}_{0} / \mathrm{L}}{\mu+\beta}\right. \\
& \left.+\frac{1}{\mathrm{~L}} \int_{-\mathrm{L}_{0}}^{\mathrm{L}_{0}} \frac{\mathrm{dz}}{\mu\left(R / R_{0}\right)^{4}+\beta\left(\mathrm{R} / \mathrm{R}_{0}\right)^{2}}\right\}, \\
\tau_{\mathrm{wm}}= & \frac{(1-\mathrm{C})}{\mu}\left(\mathrm{R} / \mathrm{R}_{0}\right)^{3}+\beta\left(\mathrm{R} / \mathrm{R}_{0}\right) \\
\tau_{\mathrm{sm}}= & \frac{(1-\mathrm{C})}{\mu\left(1-\delta / \mathrm{R}_{0}\right)^{3}+\beta\left(1-\delta / R_{0}\right)}
\end{aligned}
$$

The second subscript $\mathrm{m}$ stands for the quantities associated with the flow of a single-layered macroscopic two-phase blood flow. Further, it is interesting to note that in the absence of the particle phase in the core region, the two-phase fluid in the core region reduces to the same fluid as in the peripheral region and consequently the role of the interface automatically disappears and one obtains the expressions for the blood flow characteristics for a single-layered Newtonian fluid as

$$
\begin{gathered}
\lambda_{\mathrm{N}}=1-\mathrm{L}_{0} / \mathrm{L}+\frac{1}{\mathrm{~L}} \int_{-\mathrm{L}_{0}}^{\mathrm{L}_{0}} \frac{\mathrm{dz}}{\left(\mathrm{R} / \mathrm{R}_{0}\right)^{4}}, \\
\tau_{\mathrm{wN}}=\frac{1}{\left(\mathrm{R} / \mathrm{R}_{0}\right)^{3}}, \\
\tau_{\mathrm{sN}}=\frac{1}{\left(1-\delta / \mathrm{R}_{0}\right)^{3}},
\end{gathered}
$$

where the second subscript $\mathrm{N}$ stands for single-layered Newtonian fluid.

\section{Numerical results and discussion}

In order to discuss the results of the study quantitatively, computer codes are developed to evaluate analytical results obtained in Equations (2.19)-(2.21) at the temperature of $37^{\circ} \mathrm{C}$ in an artery of radius $0.01 \mathrm{~cm}$ for various parameter values [34, 35, 40] 


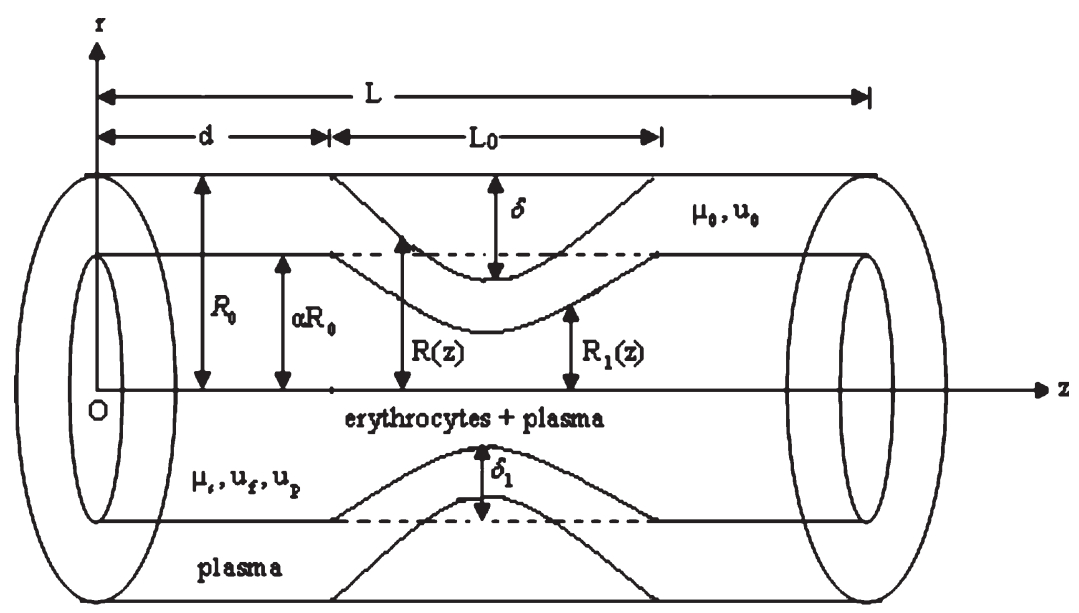

Fig. 2. The shape of the central layer.

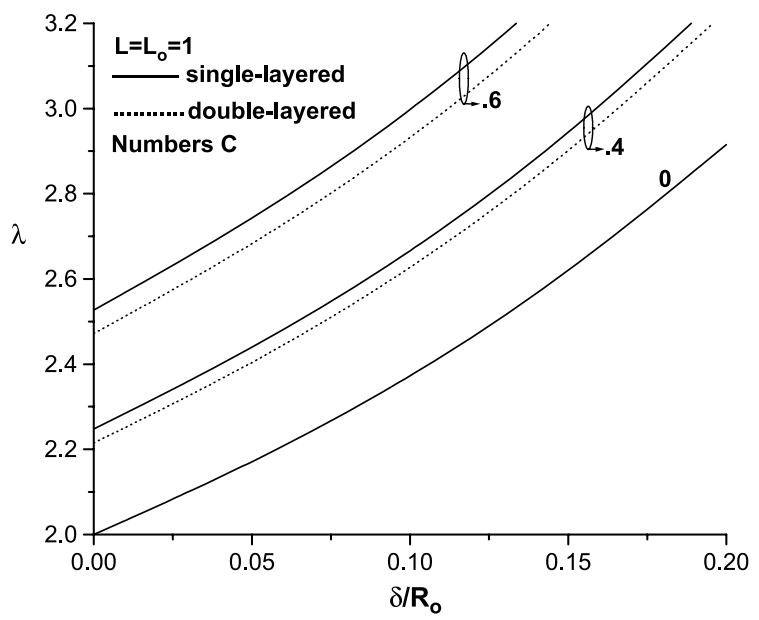

Fig. 3. $\lambda$ vs $\delta / R_{0}$ for different, C.

selected as: $\mathrm{L}_{0}(\mathrm{~cm})=1 ; \mathrm{L}(\mathrm{cm})=1,2,5 ; \mathrm{C}=0,0.2$, $0.4,0.6 ; \delta / R_{0}=0,0.05,0.10,0.15,0.20$. Some of the critical results obtained are displayed graphically in Figs. 3-8. In view of the fact that the peripheral layer thickness strongly depends on the core suspension viscosity (i.e., on erythrocyte concentration; [6, $32]$ ), we choose $2 \mathrm{a}_{0}$ (diameter of a red cell) $=8 \mu \mathrm{m}$, the peripheral layer thickness, $\varepsilon(\mu \mathrm{m}) \cong \varepsilon(\mathrm{C})=6.18$, $4.67,3.60,3.12,2.58,2.18$ corresponding to the hematocrit, $\mathrm{C}=0.1,0.2,0.3,0.4,0.5,0.6$, respectively [9]. The value of the parameter, $\alpha$ is then calculated from the relation: $\alpha=1-\varepsilon / \mathrm{R}_{0}$.

The resistance to flow, $\lambda$ increases with the hematocrit, $\mathrm{C}$ as well as with the stenosis height, $\delta / R_{0}$ (Fig. 3). The impedance, $\lambda$ decreases with the

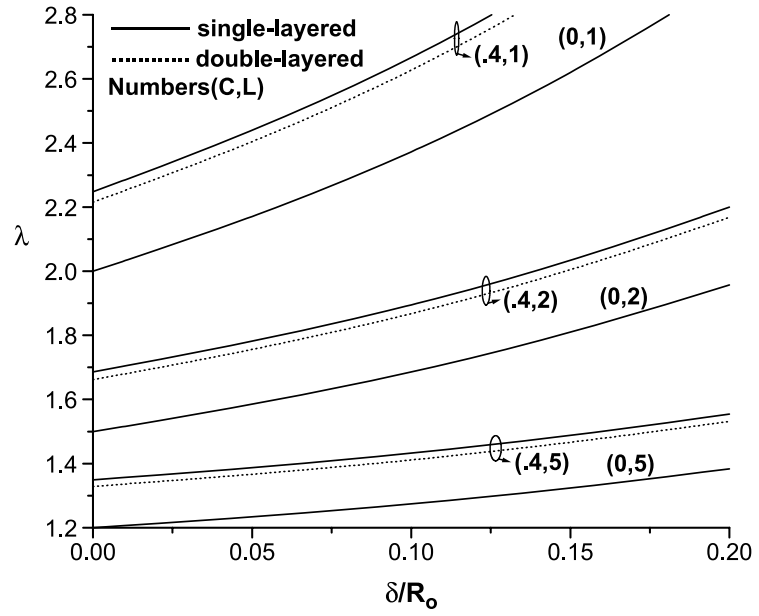

Fig. 4. $\lambda$ vs $\delta / R_{o}$ for different $C$ and $L$.

increasing length of the tube which in terns implies that the impedance, $\lambda$ increases with the stenosis length, $2 \mathrm{~L}_{0}$ (Fig. 4). The blood flow characteristic, $\lambda$ increases steeply with the hematocrit, $\mathrm{C}$ for any given set of other parameters (Fig. 5). The flow characteristic, $\lambda$ assumes lower magnitude in two-layered analysis than its corresponding value in single-layered model (Figs. 2-5).

At any axial distance the wall shear stress in the stenotic region, $\tau_{w}$ increases with the hematocrit, $\mathrm{C}$ and stenosis height, $\delta / R_{0}$ (Fig. 6). The blood flow characteristic, increases rapidly in the up stream of the stenosis throat and attains its peak magnitude at the throat located at $\mathrm{z} / \mathrm{L}_{0}=0$, it then decreases rapidly in the down stream of the throat and attains its approached value (i.e., at $\mathrm{z} / \mathrm{L}_{0}=-1$ ) at the end point of the 


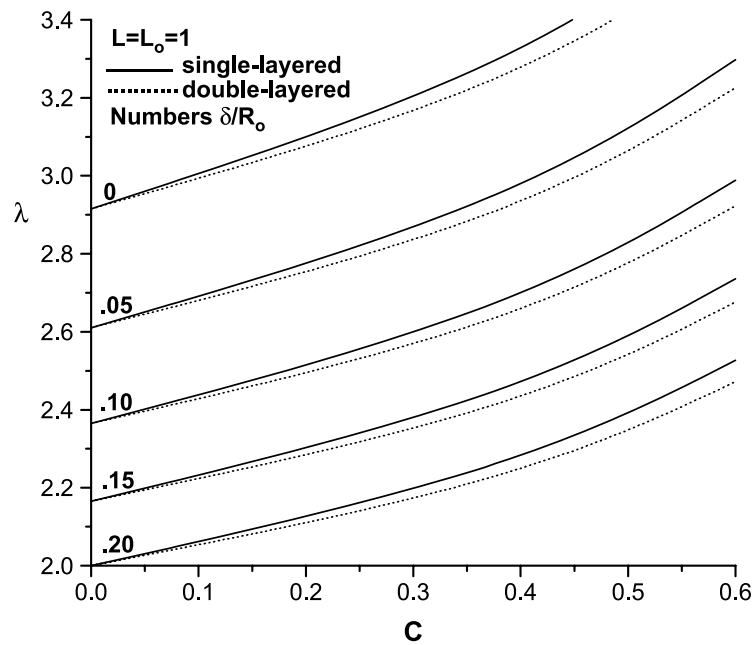

Fig. 5. $\lambda$ vs $C$ for different $\delta / R_{0}$.

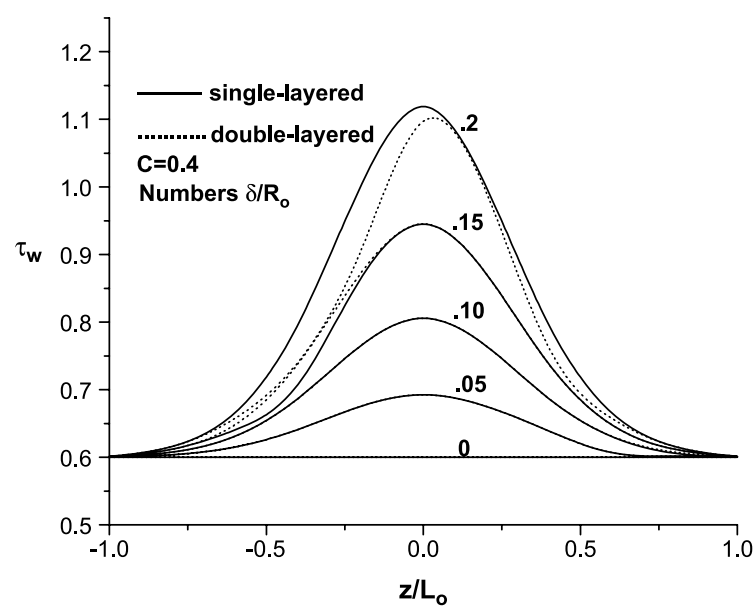

Fig. 6. $\tau_{\mathrm{w}} \mathrm{vs} z / \mathrm{L}_{\mathrm{o}}$ in stenotic region for different $\delta / \mathrm{R}_{\mathrm{o}}$.

constriction profile located at $\mathrm{z} / \mathrm{L}_{0}=1$ (Fig. 6). It is to note here that for small stenosis height, $\delta / R_{0}(\leq$ $0.1,19 \%$ stenosis by area reduction), the magnitude of the shear stress, $\tau_{w}$ in two-fluid analysis follow closely the magnitude of the shear stress, $\tau_{w}$ in one-fluid analysis but considerable difference between the two is clearly observed increasing stenosis size. In addition, one notices that the peak point of the shear stress in two-layered analysis occurs slightly right to the peak point of the shear stress in one-layered analysis. The shear stress at the stenosis in throat, $\tau_{\mathrm{s}}$ also increases with the hematocrit, $C$ and the stenosis height, $\delta / R_{0}$ (Fig. 7). An inspection of Figs. 2-4, 6 and 7 reveals

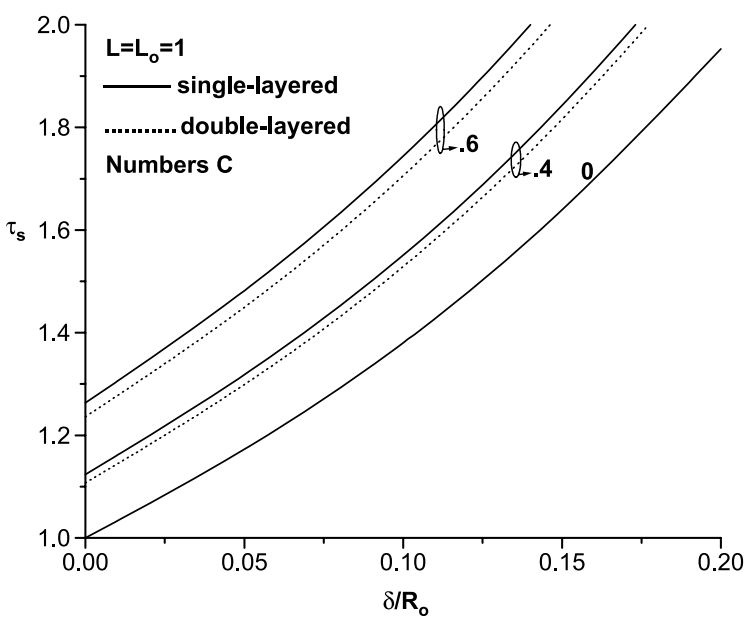

Fig. 7. $\tau_{\mathrm{s}}$ vs $\delta / \mathrm{R}_{\mathrm{o}}$ for different $\mathrm{C}$.

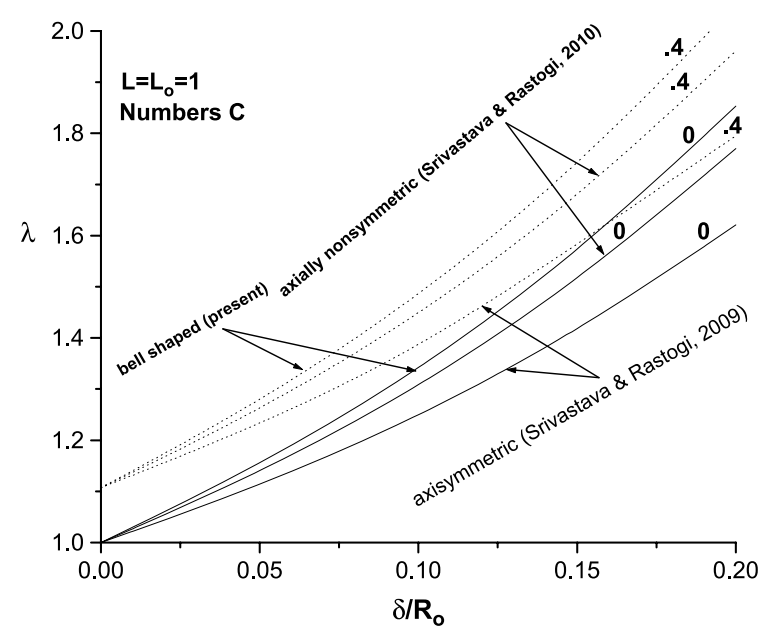

Fig. 8. $\lambda$ vs $\delta / R_{o}$ for different stenosis geometry.

that the shear stress at the stenosis throat, $\tau_{\mathrm{s}}$ possesses the characteristics similar to that of the flow resistance, $\lambda$ with respect to any parameter.

To emphasize further on the significance of the present work, a comparison of the results (impedance) obtained in the case of the present bell shaped stenosis with those obtained in an axisymmetric stenosis [34] and axially non-symmetric stenosis [33] has been presented in Fig. 8 for the same values of the various parameters. For any stenosis height, $\delta / \mathrm{R}_{0}$ the flow resistance, $\lambda$ assumes considerably higher magnitude in the present bell shaped stenosis as compared to other geometries (symmetric or non-symmetric). 
The condition that $\delta / R_{0}<<1$ limits the usefulness of the present study to very early stages of the vessel constriction, which allows the use of fully developed flow equations and closed form solutions; the use of parameter $\delta / R_{0}$ is restricted to the value up to 0.15 (i.e., $28 \%$ stenosis by area reduction) as beyond this value a separation in the flow may occur [40].

\section{Conclusions}

To observe the effects of hematocrit on blood flow characteristics due to the presence of a mild stenosis, a macroscopic two-phase model of blood has been used to discuss the flow through a bell shaped stenosis. The blood flow characteristics (the flow resistance, the wall shear stress in the stenotic region and the shear stress at the stenosis throat) increase with the hematocrit as well as with the stenosis size (length and height). The shear stress at the stenosis throat possesses the characteristics similar to that of the impedance with respect to any parameter. The two-phase fluid (particle-fluid suspension) seems to be more sensitive to the stenosis than a single-phase fluid. The flow characteristics assume considerably higher magnitude in the present bell shaped stenosis than its corresponding valve in axisymmetric and non-symmetric stenoses. The flow characteristics assume lower magnitude in two-fluid analysis than its corresponding magnitude in one-fluid study which concludes that the peripheral layer helps in functioning of diseased arteries.

\section{References}

[1] A.S. Ahmed and D.P. Giddens, Velocity measurements in steady flow through axisymmetric stenosis at moderate Reynolds number, J Biomech 16 (1983), 505-516.

[2] S. Bandyopadhyay and G.C. Layek, Numerical computation of pulsatile flow through a locally constricted channel, Commum Nonlinear Sci Numer Simulat 16 (2011), 252-265.

[3] S. Bandyopadhyay and G.C. Layek, Study of magnetodydrodynamic pulsatile flow in a constricted channel, Commum Nonlinear Sci Numer Simulat 17 (2012), 2434-2446.

[4] D. Biswas and U.S. Chakraborty, Two-layered pulsatile blood flow in stenosed artery with body acceleration and slip wall, Applc Appl Math 5(2) (2010a), 303-320.

[5] D. Biswas and U.S. Chakraborty, Pulsatile blood flow through a catherterized artery with a axially nonsymmetrical stenosis, Appl Math Sci 58(4) (2010b), 2865-2880.

[6] G. Bugliarello and J. Sevilla, Velocity distribution and other characteristics of steady and pulsatile blood flow in fine glass tubes, Biorheol 7 (1970), 85-107.
[7] C.G. Caro, T.J. Pedley, R.C. Schroter and W.A. Seed, The Mechanics of the Circulation, Oxford Medical, NY, 1978.

[8] G.R. Cokelet, The Rheology of Human Blood: In Biomechanies, Prentice-Hall, Englewood Cliffs, N.J, 1972.

[9] R.H. Haynes, Physical basis on dependence of blood viscosity on tube radius, Am J Physiol 198 (1960), 1193-1205.

[10] P. Joshi, A. Pathak and B.K. Joshi, Two layered model of blood flow through composite stenosed artery, Applications and Applied Mathematics 4(2) (2009), 343-354.

[11] H. Jung, J.W. Choi and C.G. Park, Asymmetric flows of nonNewtonian fluids in symmetric stenosed artery, Korea-Aust Rheol Journal 16 (2004), 101-108.

[12] G.C. Layek, S. Mukhopadhyay and R.S.D. Gorla, Unsteady viscous flow with variable viscosity in a vascular tube with an overlapping constriction, Int J Engng Sci 47 (2009), 649659.

[13] G.T. Liu, X.J. Wang, B.Q. Ai and L.G. Liu, Numerical study of pulsating flow through a tapered artery with stenosis, Chin Journal Phys 42 (2004), 401-409.

[14] P.K. Mandal, An unsteady analysis of non-Newtonian blood flow through tapered arteries with a stenosis, Int J of Nonlinear Mechanics 40 (2005), 51-164.

[15] P.K. Mandal, S. Chakravarty and A. Mandal, Numerical study on the unsteady flow of non-Newtonian fluid through diffrerently shaped arterial stenosis, Int J Comput Math 84 (2007), 1059-1077.

[16] F.C. Mann, J.F. Herrick, H.E. Essex and E.J. Blades, Effects on blood flow of decreasing the lumen of blood vessels, Surgery 4 (1938), 249-252.

[17] A. Medhavi, On macroscopic two-phase arterial blood flow through an overlapping stenosis, E-Journal of Science and Technology 6 (2011), 19-31.

[18] Kh.S. Mekheimer and M.A. Elkot, Magnetic field and hall currents influences on blood flow through a stenotic arteries, Applied Mathematics and Mechanics 29 (2008), 1-12.

[19] Kh.S. Mekheimer, M.H. Harun and M.A. Elkot, Induced magnetic field influences on blood flow through an anisotropically tapered elastic arteries with overlapping stenosis in an annulus, Can J Phys 89 (2011), 210-212.

[20] S. Mishra and S.U. Siddiqui, A Mathematical model for blood flow and diffusion through stenotic capillary-tissue exchange system, E-J Sci \& Tech 6 (2011), 1-17.

[21] J.C. Misra and G.C. Shit, Blood flow through arteries in a pathological state: A theoretical study, Int J Engg Sci 44 (2006), 662-671.

[22] S. Nadeem, N.S. Akbar, A.A. Hendi and T. Hayat, Power law fluid model for blood flow through a tapered artery with a stenosis, Appl Math Comput 217 (2011), 7108-7116.

[23] A.K. Politis, G.P. Stavropoulos, M.N. Christolis, F.G. Panagopoulos, N.S. Vlachos and N.C. Markatos, Numerical modeling of simulated blood flow in idealized composite arterial coronary grafts: Steady state simulations. J Biomech $\mathbf{4 0}(5)$ (2007), 1125-1136.

[24] A.K. Politis, G.P. Stavropoulos, M.N. Christolis, F.G. Panagopoulos, N.S. Vlachos and N.C. Markatos, Numerical modeling of simulated blood flow in idealized composite arterial coronary grafts: Transient flow, J Biomechanics 41(1) (2008), 25-39.

[25] R. Ponalagusamy and R.T. Selvi, Blood flow through stenosed arteries: New formula for computing peripheral layer thickness, Int J Bio-Sci \& Bio-Tech 3 (2011), 27-37.

[26] R. Ponalagusamy, Blood flow through an artery with mild stenosis: A two layered model, different shapes of stenosis 
and slip velocity at the wall, J Appl Sci 7(7) (2007), 10711077.

[27] R.N. Pralhad and D.H. Schultz, Modeling of arterial stenosis and its applications to blood diseases, Math Biosci 190 (2004), 203-220.

[28] A. Sarkar and G. Jayaraman, Corretion to flow rate-pressure drop in coronary angioplasty; steady streaming effect, $J$ Biomech 31 (1998), 781-791.

[29] J.B. Shukla, R.S. Parihar and S.P. Gupta, Effects of peripheral layer viscosity on blood flow thorough the artery with mild stenosis, Bull Math Biol 42 (1980), 797-805.

[30] B. Singh, P. Joshi and B.K. Joshi, Blood flow through an artery having radially non-summetric mild stenosis, Appl Math Sci 4(22) (2010), 1065-1072.

[31] R. Skalak, Mechanics of microcirculation: In Biomechanics, Its foundation and Objectives, Prentice Hall, Englewood Cliffs, 1972.

[32] V.P. Srivastava, A theoretical model for blood flow in small vessels, Applications and Applied Mathematics 2 (2007), $51-65$.

[33] V.P. Srivastava and R. Rastogi, Blood flow through stenosed catherterized artery: Effects of hematocrit and stenosis shape, Comput Math Applc 59 (2010), 1377-1385.
[34] V.P. Srivastava and R. Rastogi, Effects of hematocrit on impedance and shear stress during stenosed artery catheterization, Applications and Applied Mathematics 4 (2009), 98-113.

[35] V.P. Srivastava and R. Srivastava, Particulate suspension blood flow through a narrow catheterized artery, Computer and Mathematics with Applications 58 (2009), 227-238.

[36] V.P. Srivastava, R. Vishnoi and P. Sinha, Response of a composite stenosis to non-Newtonian blood flow in arteries, $E-J$ Sci \& Tech 7(2) (2012), 61-70.

[37] G.B. Thurston, Plasma release cell-layering theory for blood flow, Boirheol 26 (1989), 199-214.

[38] E.E. Tzirtzilakis, Biomagnetic fluid flow in a channel with stenosis, Physica D 237 (2008), 66-81.

[39] D.F. Young and F.Y. Tsai, Flow characteristics in model of arterial stenosis - steady flow, J Biomech 6 (1973), 395-410.

[40] D.F. Young, Effects of a time-dependent stenosis of flow through a tube, Journal of Eng Ind 90 (1968), 248-254.

[41] D.F. Young, Fluid mechanics of arterial stenosis, Journal of Biomechanics Eng 101 (1979), 157-175. 

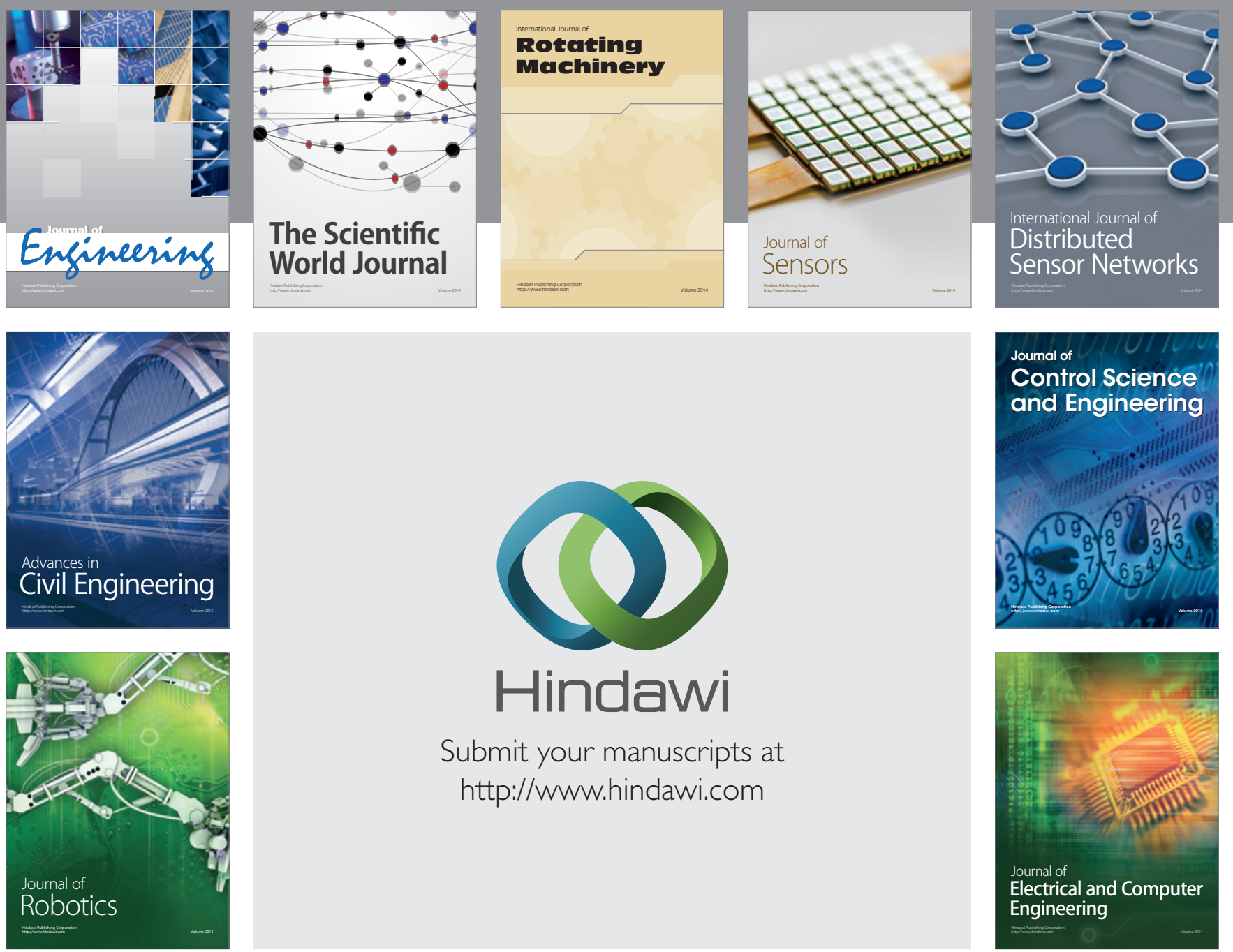

Submit your manuscripts at

http://www.hindawi.com
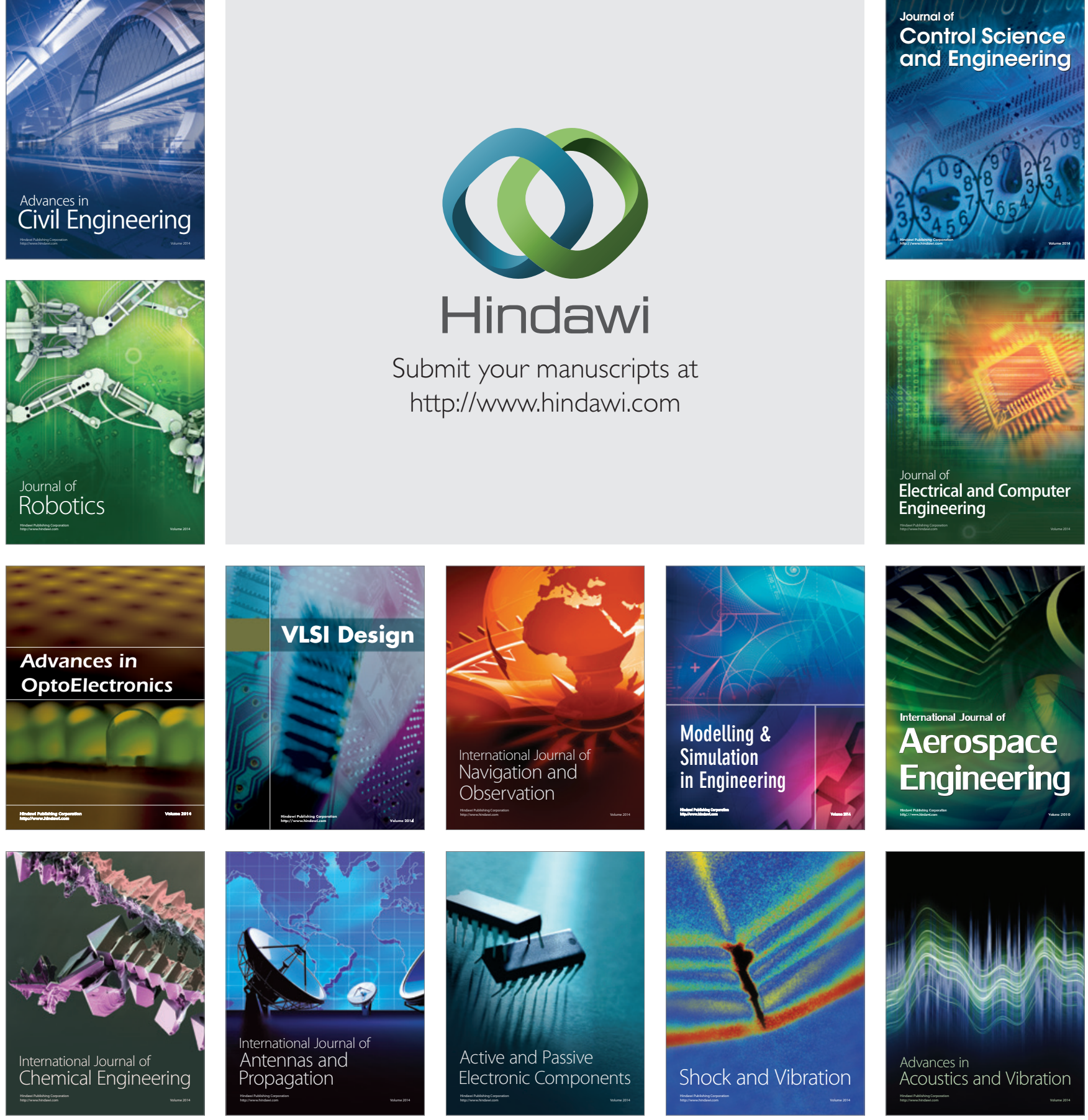